\title{
The Perils of Gender Beliefs for Men Leaders as Change Agents for \\ Gender Equality
}

\begin{abstract}
This article examines the potentially damaging role that gender beliefs can play in hindering women's equal representation in leadership positions. Based on a secondary analysis of a large-scale EU-wide survey (Eurobarometer 76.1), the article shows that essentialist gender beliefs lower support for equality interventions such as quotas or targets, particularly among men as leaders. The results show that discriminatory gender beliefs partially mediate this relationship and produce a more negative effect among men leaders. The paper contributes to understanding the role essentialist gender beliefs often lay the groundwork for gender discriminatory beliefs. Those in turn hinder support for effective gender equality measures. Gender essentialist beliefs can be held by everyone but are more prevalent among men leaders. We conclude that greater gender balance in leadership cannot be achieved without tackling underlying gender beliefs, particularly among men leaders since they are called upon to enact change. We thereby argue that simply asking for men to become change agents for gender equality is not an effective strategy if underlying gender beliefs are left unchallenged.
\end{abstract}

Keywords: gender, leadership, quotas, essentialism, men, targets, beliefs

\section{Introduction}

The under-representation of women as leaders on the boards of publicly quoted companies remains salient in the EU, where in 2015 an average of $23 \%$ of boards members were women across its Member States - ranging from 5\% in Malta to 36\% in France (European Commission, 2015). To counter these inequalities, several European countries introduced 
mandatory or voluntary quotas for board positions. In 2003, Norway was the first country to introduce mandatory quotas when women's board representation in listed companies increased only from 4\% in 1992 to $6 \%$ in 2002 despite voluntary measures. These mandatory quotas were more effective: by 2008, $40 \%$ of board members were women (Huse and Brogi, 2013; Machold et al., 2013). Several countries, such as Italy or France followed Norway's example and introduced mandatory quotas in recent years.

The potential for quotas or targets to redress the imbalance has been acknowledged (Storvik and Teigen, 2010) but at the same time have proved highly controversial and divisive (Tienari et al., 2009; Seierstad, 2013; Terjesen et al., 2015). Quotas and targets need to be analysed in a context where the rhetoric of merit and choice are strong in the business community (Broadbridge and Simpson, 2011; Vinkenburg, 2017). This creates the ideal of organizations as meritocracies, a social system where talent and merit alone dictate who receives advancements or rewards (Scully, 1997; Castilla and Benard, 2010) without influence from other factors such as sex. Resistance to quotas in particular might be fuelled by the perception that quotas threaten this meritocratic system (Noon, 2007), as in the case of the UK where the threat of quotas has motivated voluntary actions but where quotas remain unpopular (Terjesen and Sealy, 2016). This ideal of meritocracy implies that gender inequalities are instead attributed to essentialist beliefs about the traits and/or preferences of women and men rather than to a system in which systematic biases prevent equal opportunities. Essentialist beliefs associate an underlying 'essence' to some groups of people, for example on the basis of sex (Brescoll et al., 2013). This essential nature can be seen as being at odds with women's perceived suitability for board positions (Billing and Alvesson, 2000; Eagly and Karau, 2002) and may create resistance to quotas. 
To further our understanding of resistance to quotas, it is necessary to examine how they relate to essentialist beliefs about gender, and in particular to the taken-for-granted assumption that organisations are meritocratic. Hitherto, the empirical link between essentialist gender beliefs and support for gender equality measures such as quotas or targets has remained largely unconsidered. The central aim of this paper is thus to examine how essentialist gender beliefs relate to support - or otherwise - for legislated board quotas or other legislated measures, and particularly so among leaders given how they frame women's success in organisations (Liff, Worrall and Cooper, 1997). The article examines whether essentialist beliefs that women and men are different in traits and preferences decreases support for gender equality measures such as quotas or targets. We suggest that this may be explained by system justification theory (Jost and Banaji, 1994; Jost et al., 2004), whereby individuals are both victims and supporters of the norms embedded in organisations regardless of whether this is in their interest or not. The potential mediation effect of discriminatory gender beliefs is also examined. The paper goes further by asking whether this relationship is stronger among men leaders, the group that is potentially most advantaged by current gender inequalities in organisations. Social identity theory - which unlike social justification theory focuses on the attitudes or behaviours of the in-group (Jost et al., 2004) is used as a lens here to examine how a more advantaged group reifies inequalities (Tajfel, 1981; Tajfel and Turner, 2004).

In this paper, we contribute to the emerging literature on the role of men leaders in change interventions on gender equality (de Vries, 2015; Kelan and Wratil, 2018). This literature advocates for better insights of the role of men in gender change initiatives. Catalyst supported the view that before individuals will support or advocate for gender equality measures they must first recognize that the inequality exists (Prime and Moss-Racusin 2009). 
With most leadership positions dominated by men, men are in a central position to drive gender equality. Yet men are often seen as roadblocks for gender equality (Cockburn 1991; McKinsey, 2012) and their lack of engagement means that change initiatives around gender often fail (Eriksson-Zetterquist and Renemark, 2016). It is in fact often men who are seen as effective change agents on gender equality because women advocating on behalf of women are often seen as self-interested (de Vries 2015; Hekman et al., 2017). However there is limited research on the role that men can play as change agents for gender equality (Kelan, 2018). It has also been questioned in how far men are interested in debunking their own privilege to achieve gender equality (de Vries 2015). So far, there is limited research that explores the role of men in gender equality efforts.

Our analysis relies on Eurobarometer 76.1, a large-scale representative opinion survey conducted in the EU in 2011, which provides the means to examine gender beliefs (European Commission and European Parliament, 2014). The results show that essentialist gender beliefs, such as seeing men and women as 'naturally' different, are used as a justification for gender inequalities in leadership and are therefore negatively related to effective measures such as legislated board quotas. We then turn to the mediating role of discriminatory gender beliefs, before conducting the analysis specifically amidst men as leaders. We show that, despite the diversity of beliefs held by women and men, the negative relationship between essentialist gender beliefs and support for quotas or other legislated measures is stronger among men leaders. Resistance, particularly within organisational leadership is thus apparent, prompting the urgent need to tackle essentialist gender beliefs before any real change in practice can be achieved. 


\section{Essentialist gender beliefs and quotas}

One of the most successful measures of late to address gender inequalities in organisations is the implementation of board quotas (Bertrand, Black, Jensen and Llearas-Muney, 2014; Terjesen et al., 2015), despite persisting inequalities above that level. Although quotas are imposed at the national level, organisations are active participants both for and against this potential legislation (Terjesen and Sealy, 2016). Yet, despite their effectiveness quotas have proven to be highly divisive and subject to much resistance (Tienari et al., 2009; Terjesen et al., 2015). In the quota strategy, resistance seems unavoidable, as it aims at disturbing the status quo and does not rely on consensus in the entire organization. The literature shows that privileged groups are less in favor of (radical) interventions. Privileged professional men may resist the perceived loss of control (Ashcraft, 2005) over the allocation of those positions and refuse to accept their diminished chances to land such positions. In addition, professional women may also resist the quota for they want to be granted top positions because of their qualities, not because of their sex (van den Brink and Stobbe, 2014).

The introduction of quotas invokes a highly charged ethical dilemma, contesting the meanings of key concepts such as 'merit', 'discrimination' and 'fairness' (Benschop and van den Brink, 2014; Browne, 2014). In Norway, the quota legislation met strong resistance from within companies. The main arguments of the opponents were justice, skills and democracy (Storvik and Teigen 2010). Quota regulations were considered to be illegitimate unequal treatment and a discrimination against men. They feared that less skilled women would take over the place of experienced and skilled men. It was also claimed that the quota law would hamper owners' democratic right to recruit candidates and, in particular, interfere with the election process at the stakeholders meeting. In the Netherlands, a quota for top police offers was heavily resisted because of similar reasons (van den Brink \& Benschop, 2018). 
Opponents had concerns about the challenge to meritocracy values, the challenge to quality, the decrease of men's career possibilities and the 'violation' of meticulous and transparent procedures.

The underlying assumption of such arguments is often that women simply have different preferences when it comes to investing into work or family life: some women prioritise work, others prioritise family and the majority is trying to combine work and family (Hakim, 2000). If a small proportion of women is work centred, proponents of preference theory suggest that women are less likely to be competing for management positions that can lead to board roles. However scholars have contested preference theory by for instance pointing out that the concept of women choosing different lifestyle models is in itself a product of current social and economic constructions (Lewis and Simpson, 2017). Another set of underlying assumptions relate to men's inability to be appointed to boards. While it could be assumed that a target or quota makes it impossible for men to become board members, it has been shown that even in times when there is an increased focus on increasing the representation of boards, men still gain the lion's share of board roles in the UK (Brown, Kelan \& Humbert, 2015). However it has been shown that even if women are included into board roles, the women recruited onto UK boards often come from a similar privileged class background as men who are already on boards (Brown, 2016). This means that women but also men from different class backgrounds will be less likely to be appointed to boards.

We propose that to better understand resistance to quotas, it is necessary to examine how legislated measures relate to essentialist beliefs about gender, and in particular to the myth of the meritocratic organisation. 
Much of the resistance to quotas can be seen as stemming from seeing them as a threat to a system that is perceived as meritocratic where inequalities are the result of natural abilities and individuals preferences (Noon, 2007) and the belief that the 'gender problem' has been solved (Broadbridge and Hearn, 2008; Broadbridge and Simpson, 2011). Merit is underpinned by criteria, but these can be manipulated and used to justify discriminatory decisions (Bozionelos, 2005). As Uhlmann and Cohen (2005, p. 479) argue, "prejudice often expresses itself in rationalisable ways that allow people to maintain an image of themselves as objective and principled. Meritocratic principles are violated, however, when merit is flexibly defined to the advantage of certain groups". Indeed, organisations are no longer regarded as gender neutral by many scholars in the field of gender and management, with a recognition that gender operates as a central organising principle for leadership that both constructs and reifies gender inequalities (Acker, 1990; Martin and Collinson, 2002; Britton and Logan, 2008; Broadbridge and Hearn, 2008). This includes recognising that organisations are largely constructed by men for men, creating an attainable standard in the shape of hegemonic forms of masculinities against which both men, but particularly women, are judged and expected to compete (Connell, 1998; Martin, 2001; Connell and Messerschmidt, 2005).

Expectations are that congruence with the ideals of hegemonic masculinities brings about rewards such as promotions and advancement within the organisation and that this equally available to both women and men. If women do not advance and reach leadership positions, it is attributed to their failure to fulfil a model that is shaped by values that draw on masculine values and establishes the congruence between men and leadership (Heilman, 2001; Eagly and Karau, 2002; Heilman and Eagly, 2008; Eagly and Chin, 2010). However, 
women as a group are less likely to fit in with this ideal norm of masculinity because there is a misalignment between expected gender roles and the assigned gender label of a position (Benschop and Doorewaard, 1998; Billing, 2011), famously labelled 'think manager, think male' by Schein (1973). Unfortunately, as this remains largely invisible, organisations continue to be perceived as meritocratic (Krefting, 2003; Broadbridge and Simpson, 2011).

\section{Explaining women's underrepresentation through essential differences}

Instead, women's lack of representation as leaders is often perceived as rooted in individual traits and preferences in which women have agency (Gill, Kelan and Scharff, 2017) which fuels popular beliefs that women are not represented in leadership because they are not sufficiently 'leaning in' (Sandberg, 2013). Women's lack of advancement in organisations and ultimately in leadership positions - is seen as the result of a 'lack of' key capital such as relevant education or experience, but also because they opt to give preference to family responsibilities over commitment to their careers (Broadbridge and Hearn, 2008). These individual level explanations for women's underrepresentation as leaders feed from essentialist beliefs about differences between women and men. Essentialism is the association of an underlying 'essence' to people with a particularly group membership, in the case of gender on the basis of sex (Brescoll, Uhlmann and Newman, 2013, p. 891). This often comes with an implied biological causation (Bem, 1993; Haslam and Whelan, 2008), for example that the division of labour is justified by women's natural inclination for a nurturing role. However, a link to biology does not have to be present, such as when considering the essence of being a teacher or a scientist. In their review of the concept, Brescoll and colleagues (2013) point out that essentialist beliefs may be universal since they apply across geographical areas and are present even in young children. Essentialist beliefs are not in themselves detrimental, unless they involve causal links that are inaccurate. 
Essentialist explanations to justify gender inequalities are widespread (Fausto-Sterling, 1985; Bem, 1993; Haslam and Whelan, 2008), including when it comes to women's representation in leadership (Billing, 2011; van den Brink and Benschop, 2014). Essentialist gender beliefs lead to the problematisation of women's choices and priorities, and it is taken for granted that leadership remains the preserve of men. Women rather than organisations appear in need to be fixed (Ely and Meyerson, 2000). Women adapt to the context, not only organisational but also societal. Essentialist gender beliefs vary in different societies, yet in all societies lead to behaviours being valued differently for women and men at work (Mor Barak, 2016). The underrepresentation of women in leadership positions is therefore closely tied to cultural beliefs about gender roles, whereby women's lower representation "validates entrenched systems and beliefs that prompt and support men's bids for leadership, which in turn, maintains the status quo" (Ely, Ibarra and Kolb, 2011, p. 475).

The reliance on gender essentialism to explain gender differences can be understood through the lens of system justification theory which argues that the system is perceived as just and fair, leading people to engage in a number of strategies to justify this belief (Jost and Banaji, 1994; Jost, Banaji and Nosek, 2004). Social systems are perceived as inherently fair, with inequalities rationalised (Jost and Banaji, 1994). All groups, women and men in all their diversity, engage in justifying the status quo: "hierarchy is maintained not only through mechanisms of ingroup favouritism and outgroup derogation exercised by members of dominant groups, but also by the complicity of subordinated groups, many of whom perpetuate inequality through mechanisms such as outgroup favouritism" (Jost et al., 2004, p. 7). As such, social justification theory is useful to explain the degree of stereotype consensus 
across groups. It recognises that both low and high status groups contribute to the legitimization of the system.

Brescoll et al. (2013, p. 897) propose that the justification of inequalities, in the case of gender, is done through the attribution of essential causes to group differences to justify the "legitimacy of the hierarchy". Stereotypes are used as a distinguishing feature of status between women and men to make "inequality seem natural and appropriate" (Jost et al., 2004, p. 12). Studies find a positive link between essentialist explanations of gender differences and their use in justifying the system (Keller, 2005). Brescoll et al. (2013) experimentally demonstrate for example, that a perceived threat to the social system increases the endorsement of biological determinism. In our case, we propose that the system is seen as fair and meritocratic and that gender equality measures, including effective ones such as quotas, are perceived as a threat. Board quotas can be perceived as advantaging women somewhat unfairly, particularly if this is inscribed in an understanding of gender equality that is no longer relevant and in which sexism itself is denied (Gill et al., 2017). Using the lens of system justification theory, persisting gender inequalities are then justified by resorting to essentialist gender beliefs. We therefore propose the following hypothesis:

H1. Higher levels of essentialist gender beliefs will be negatively related to supporting legislated measures such as board quotas or targets.

\section{The mediating role of discriminatory gender beliefs}

Discrimination itself remains the chief culprit to explain women's underrepresentation as leaders (Eagly and Carli, 2016). Essentialist beliefs play a key role in creating prejudice and discrimination (Haslam et al., 2002; Haslam and Whelan, 2008) and lack of parity may lie in the fact that many cultures share the belief that women should not have authority over men 
(Padavic and Reskin, 2002). However it could also be because there are deep-seated interests in maintaining the status quo (Ridgeway, 2001) and as a result, the risk of a backlash against any progress made (Eagly and Carli, 2007). The perception of the legitimacy of women to occupy spaces as leaders on corporate boards is therefore likely to play a significant role in relation to supporting board quotas or other legislated measures. Being in favour or opposed to legislated quotas is potentially deeply related to beliefs about whether women ought to be equally represented in leadership positions.

As such, what our first hypothesis fails to consider is the extent to which there may be resistance to women's access to leadership positions that stems from discrimination rather than simply essentialist gender beliefs. This warrants the introduction of discriminatory beliefs as a potential mediator. We propose that not only may essentialist gender beliefs lead to discriminatory gender beliefs (Haslam and Whelan, 2008), but also that this in turn leads to lack of support for quotas (or any other effective gender measure). Through examining this mediation, we argue that holding essentialist gender beliefs is not in itself detrimental unless it is associated with discriminatory beliefs. The question becomes whether lack of support for gender equality initiatives are related to essentialist beliefs (direct path) or whether essentialist beliefs are only problematic insofar as they produce discriminatory beliefs, which then hinder support for gender equality initiatives. In other words, we propose the following hypothesis:

H2. Holding discriminatory beliefs will mediate the relationship outlined in $\mathrm{H} 1$.

\section{Men leaders' attitudes towards gender change in organisations}

The central role that top leaders play in effecting gender equality at organisational level has often been cited through their ability to shape organisational cultures and practices (Liff et al., 
1997; Schein, 2010; Kelan, 2018; Kelan and Wratil, 2018). For example, Konrad and Linnehan (1995) found an important positive relationship between leaders' attitudes and the effectiveness of gender equality actions. Since men remain over-represented in top leadership positions, the focus has been on engaging men as leaders to ensure that women are increasingly represented on corporate boards (Bilimoria, 2000; Carter, Simkins and Simpson, 2003; Noon, 2007). Calls for men to act as equality change agents assumes that support largely exists for women as leaders, yet leaves the resistance to the incorporation of women on boards unproblematised. Change is seen as the remit of powerful men, that are assumed to have the will to change the status quo (de Vries, 2015). However, change is neither power nor gender blind. Changing gender relations is as much about women as about men, transformative change necessarily implies changing gendered cultures: addressing women's under-valued positions means also addressing men's over-valued positions (Hearn, 2004). This is not to say that all men in positions of power are alike, but instead that their practices of gender at work conforms to the ideal norms of hegemonic forms of masculinities (Martin, 2001). It is in fact powerful men that have the most to lose and the least incentive to want to change the status quo (Acker, 2000, 2006; Benschop and Verloo, 2006; de Vries, 2015), although this does not apply universally to all men in positions of power. This can create much resistance and little effectiveness, as illustrated by Konrad and Linnehan (1995) who note that in many instances equality policies within organisations are used to display what they call 'good faith' in organisations rather than have any real effect.

In the process of change, leaders can be seen as 'gatekeepers'. Gatekeeping can serve two functions: exclusion and control but also inclusion and facilitation (Husu, 2004). As van den Brink and Benschop (2014, p. 464) argue: "gatekeeping implies the power of elites to grant privileges and allow access to some and deny it to others". Gatekeeping processes can 
take place at the individual level through homophily (McPherson, Smith-Lovin and Cook, 2001), etymologically 'the love of the same' but referring to the tendency for individuals to associate and bond with similar others, and at the collective level through the process of 'affiliating masculinities' (Martin, 2001). Powerful men tend to connect and socialise with men that look like them (Stafsudd, 2006; Nielsen, 2009), both through chance where the pipeline is biased and by choice as they often prefer to work with other similar men. For example, van den Brink and Benschop (2014) in their study of network practices of academic leaders found that this applied to coaching younger men that they identify as younger versions of themselves or dismissing women due to their presumed family-orientation.

The role of men, and particularly those in leadership positions is therefore of interest since as a group they have the most self-interest to maintain a status quo of inequalities in organisations. While social justification theory explains how inter-group attitudes legitimise social structures regardless of personal or group interest (Jost and Banaji, 1994; Jost et al., 2004), social identity theory (Tajfel and Turner, 2004) assumes that people will rely on visible characteristics to identify with others and construct bonds, creating in- and out-groups. Rather than focusing on all groups, social identity theory instead sheds lights on the most advantaged group(s) and the mechanisms through which they reproduce a system of inequalities. Gender acts as a major visible and dividing category that is used as the basis of segregation. Men as leaders are thus more likely to associate leadership positions with masculine attributes that are similar to their own (and 'essentially' different from women) and to attribute less favourable ratings to any groups that is perceived as distant from their own. In turn, this makes men leaders more likely to exclude women from leadership positions because of the greater distance between their own identity and the perceived one of women as a whole (Turner, Hogg, Oakes, Reicher and Wetherell, 1987). For example, Nielsen and Huse 
(2010) show that men board members are more likely to negatively rate women's ability to contribute to the board, with their beliefs having practical consequences such as women's ability to positively impact the board's strategy and decision-making. In this article, we argue that combining social identity theory and system justification theory provides an explanation of why turning to men leaders as agents of change for improving gender equality in organisations might not fully deliver. We propose that reliance on in-group ideology props up the legitimacy of the dominant group when the status quo is under threat, as in the case of effective gender equality measures such as quotas. As Morton and his colleagues argue (2009), while prejudice is related to essentialist beliefs, this link is often made by members of a higher status group where they feel that their advantaged status in under threat. We thus propose the following hypotheses:

H3. Being a man and a leader will moderate the relationships hypothesised in $\mathrm{H} 1$ and H2. Specifically, (H3a) the relationship between higher levels of essentialist gender beliefs and discriminatory gender beliefs will be more positive for men leaders; and (H3b) the relationship between higher levels of essentialist/discriminatory gender beliefs and support for legislated measures such as quotas or targets will be more negative among men leaders.

\section{Methods}

The set of hypotheses above is used to derive an analytical model, which graphically can be represented as in Figure 1. The model includes a measure of beliefs about the differences between women from men to explain their under-representation as leaders and support for legislated measures such as quotas or targets. It also includes discriminatory gender beliefs as a mediator to this hypothesised relationship. Finally, the potential moderating effects of being a man leader are examined. 
Figure 1 about here

This article responds to the need to use quantitative methods that go beyond solely disaggregating by sex (Kelan and Humbert, 2016) and instead focuses on gender beliefs. Beliefs have been neglected in the literature given how difficult they are to measure compared to more visible and readily available variables (for exceptions, see Huse et al., 2009; Nielsen and Huse, 2010). For example, work drawing on upper echelons theory (Hambrick and Mason, 1984; Carpenter, Geletkanycz and Sanders, 2004; Hambrick, 2007) relies conceptually on characteristics such as experiences, values or personalities. Testing these theories usually involves drawing on observable characteristics such as sex, education or age as proxies for values, perceptions or cognitions (Carpenter, Geletkanycz and Sanders, 2004; Dezsö and Ross, 2012; Post and Byron, 2015) despite evidence that they are a poor substitute (Mannix and Neale, 2005). This study adopts a unique approach by studying beliefs directly rather than using proxy variables.

By using gender beliefs, the analysis avoids a methodological reliance on 'essential' differences between women and men, the topic at the heart of this analysis. It subsequently introduces a variable that aims at measuring differences between women and men as leaders. In line with problematising essential differences, it is important not to understand this as a universal claim on what all wo/men leaders' attitudes are. Instead, the interpretation of this proxy ought to be nuanced and understood as a general tendency. While statistical differences may be present between women and men, this does not necessarily exclude many similarities across individuals. 


\section{Data}

The paper relies on the analysis of secondary data generated through a Eurobarometer survey conducted throughout the European Union in September 2011 (European Commission and European Parliament, 2014). Eurobarometer surveys are public opinion surveys conducted by the European Commission twice a year since 1973, on a variety of topics. Eurobarometer surveys cover a wide and representative range of the European population. In their design, efforts are made to ensure representativeness through criteria such as sex, age or location. Furthermore, careful planning goes into the design of the questionnaire and wording of the questions. Even if overall the quality of Eurobarometer data is deemed to be high (Desaint and Varbanova, 2013), they are not without limitations. Eurobarometer surveys seek opinion data and respondents may have little knowledge and/or concern for the issue, which in turn limits the validity of their answers. Nonetheless, Eurobarometer data have been regularly used for scientific publications on a range of topics, including on gender and diversity (e.g. Leong and Ward, 2006; Lagaert and Roose, 2018).

The Eurobarometer 76.1 (September 2011) explores the topic of women in decision-making throughout the then 27 EU Member States. With a total sample of 26,856 individuals (typically with close to 1,000 individuals in each country with exception of Luxembourg and Malta where the sample is limited to about 400), this survey thus provides a valuable source of information on attitudes towards women in decision-making, including beliefs of why women are less likely to hold positions of responsibility; whether given equal competence women should be equally represented in positions of leadership in companies and why; what is the perceived best way to achieve a more balanced representation; what targets potential legislation should adopt and within what time frame; what are the perceived most effective sanctions; and finally whether measures should be adopted at national and/or EU level. 
Respondents must be residents in the respective countries (nationals and non-nationals from an EU country) and aged 15 years or over.

The structure of the sample consisted of $54 \%$ of women out of 24,593 individuals. Their ages range from 15 to 98 years, with a mean of 48 years (SD 18 years): $12 \%$ are below $25 ; 32 \%$ between 25 and 44; $35 \%$ between 45 and 64; and 22\% 65 or above. A t-test showed that there are not significant different in age between women and men. Nearly half (49\%) are in employment or self-employment. Among those without an activity, 28\% are retired or unable to work due to illness, $8 \%$ are unemployed, $8 \%$ are students and $7 \%$ are home-makers. Leaders only represent a fraction of the sample, just above $1 \%$ with a total of 275 individuals. Of these, the majority (183) are men.

\section{Measures}

Independent variable: essentialist gender beliefs are captured through a latent variable that consists of three measures $(\alpha=0.71)$, in response to the following question "At the present time, in the EU, women are less likely than men to hold positions of responsibility. Please tell me whether you agree or disagree with each of the following statements on this subject" (question QE1). These three items consist of:

- Women are less interested than men in positions of responsibility (coded as interest)

- Women are less willing than men to fight to make a career for themselves (coded as will to fight)

- Women do not always have the necessary qualities and skills to fill positions of responsibility (coded as appropriate qualities and skills) 
These are measured on a 4-point Likert-type scale, reversed for ease of interpretation (higher scores are associated with higher levels of essentialist gender beliefs), where 1 stands for 'totally disagree'; 2 for 'tend to disagree'; 3 for 'tend to agree' and 4 for 'totally agree'.

Dependent variable: support for legislated measures such as quotas or targets is measured through question QE5 - "Some European countries (e.g. France, Spain, the Netherlands, Italy, Belgium and Norway) have already taken legal measures to ensure a more balanced representation of men and women on company boards. Are you in favour or opposed to a legislation on this matter under the condition that qualification is taken into account without automatically favouring one of either gender?". This relies on a 4-point Likert-type scale, reversed for ease of interpretation, where 1 stands for 'totally opposed'; 2 for 'somewhat opposed'; 3 for 'somewhat in favour' and 4 for 'totally in favour'.

Mediator: discriminatory gender beliefs is captured through question QE2 - "Do you agree or disagree with the following statement: Given equal competence, women should be equally represented in positions of leadership in companies". This is measured on a 4-point Likert-type scale where 1 stands for 'totally disagree'; 2 for 'tend to disagree'; 3 for 'tend to agree' and 4 for 'totally agree'. Higher scores stand for higher levels of discriminatory gender beliefs.

Moderators: Sex was recorded in the survey through question D10, and coded as binary category with 0 standing for men and 1 for women. Age was captured through question D11. Being a leader was obtained from question D15a through the category 'General management, director or top management (managing directors, director general, other director)'. This represents $1 \%$ of the sample. The large size of the sample nevertheless 
allows for meaningful analysis at EU level, since this represents a subsample of 275 leaders of which 183 are men. An interaction terms was then computed, providing a dummy variable that could be used for men leaders. Finally, a dummy variable was created to provide information on the EU Member States that had introduced quotas by 2011 (Belgium, France, Italy and Spain) and those that had not, coded as 1 and 0 respectively.

\section{Analyses}

Cases where responses were missing for more than one of the items and where the response to the dependent variable was missing were deleted, resulting in a sample of 24,593 individuals. A correlation metric for the numerical variables is presented in Table 1 . Correlation coefficients for countries are not presented for the sake of brevity, with none above \pm 0.15 . Missing values were imputed using the median observation for the concerned variable. There were few missing values, ranging from none for the dependent variable (QE5) to $1 \%$. In total, 23,802 individuals had no missing items, representing nearly $97 \%$ of the sample. Little's test showed that data were not missing completely at random (MCAR). Further analyses showed that being a leader or not is not associated with missing items, however, men are more likely not to respond. Interestingly men leaders were not less likely to respond to questions about essentialist beliefs, but only to discriminatory beliefs (Chi-square, $\mathrm{p}<0.01$ for all associations). The full model was run with only complete cases, with only marginal differences compared to results using imputed data.

Table 1 about here

The analysis uses IBS SPSS Amos (version 24) with maximum likelihood estimation to assess the factorial structure of the hypothesised model. As a first stage, the reliability of the 
measure for assessing how women were positioned as different from men was evaluated. Subsequently, the mediation analysis was done in line with the four steps established by Baron and Kenny (1986). The fit of the model is reported using the overall chi-square measure, comparative fit index (CFI) and the root mean square error of approximation (RMSEA) which represents the most widely used fit measures in structural equation modelling. Other measures were assessed, such as the Tucker-Lewis Index (TLI), goodnessof-fit index (GFI) but for brevity are not reported (Tucker and Lewis, 1973; Bentler, 1990; Hu and Bentler, 1999).

The analysis relies on Likert-type scales rather than Likert scales. Likert scales were originally developed by Rensis Likert (1932) to measure attitudes. Likert scales consist of a range of responses - originally from 1 to 5 - which combined together provide a measurement for the concept of interest (Croasmun and Ostrom, 2011). Likert scales have been used extensively in the Business and Management field: a search of 'Likert' within the European Management Review alone yielded over 50 articles. Methodologically, it is important to distinguish between Likert scales and Likert-type items (Clason and Dormody, 1994; Boone and Boone, 2012). Likert-type items make use of different response alternatives, but unlike Likert scales do not combine them in to a single score for use in further analysis. The distinction has implications when it comes to assumptions about the level of measurement. Likert scales are typically analysed as interval data since they are composite scores (Boone and Boone, 2012), but Likert-type items can be regarded as either interval or ordinal data. Whether it is acceptable to assume that Likert-type items and Likert scales can be regarded as interval data depends on being able to establish a sufficient correspondence between what is measured and the numbers representing different categories. In this correspondence, interval data implies assuming equidistance between the numbers used in the 
item. This analysis assumes that the Likert-type items used are, or at least approach, interval data. Post-hoc tests were conducted to assess this assumption. The models were re-run after dichotomizing the Likert-type items in the original analysis. This showed only marginal differences and did not affect the conclusions, suggesting that it is reasonable to treat the Likert-type items as approximating interval data.

\section{Results}

This section outlines the results of the analysis outlined above. It first presents a descriptive analysis of the measures. It then sets out how beliefs about whether company boards should be gender-balanced mediate the relationship between essentialist gender beliefs and support for legislated measures such as board quotas or targets. Finally, it examines the extent to which being a man leader moderates these relationships.

The data suggest that there is broad disagreement that women are less likely than men to hold positions of responsibility because of agentic reasons (Table 2). Nearly half of people (46\%) totally disagree that women do not have the necessary skills and positions to fill positions of responsibility. Furthermore, 35\% totally disagree that women are less interested in positions of responsibility and $33 \%$ that women are less likely to fight to make a career for themselves. These numbers, nonetheless, show that a non-negligible proportion of the population - both women and men - perceives women as different from men and displays essentialist gender beliefs.

Table 2 about here

The majority of respondents agreed that given equal competence, women should be equally represented in positions of leadership in companies (58\%) and only a minority 
showing very overt discriminatory gender beliefs $(2 \%)$. The level of agreement diminishes substantially when it comes to addressing this through legal provisions such as board quotas, with only $40 \%$ totally in favour of quotas given equal qualification (Table 2).

If both women and men can hold essentialist and/or discriminatory gender beliefs, there are nonetheless important gender differences amidst all the measures considered. Women are less likely to hold high levels of essentialist gender beliefs and discriminatory gender beliefs, as well as more likely to be in favour of legislated measures such as quotas (for all five variables, $\mathrm{p}<0.01$ ).

The data show that leaders are more likely than the rest of the population to have higher levels of discriminatory gender beliefs: $17 \%$ of leaders totally or tend to disagree that women should be equally represented as leaders given equal competence, compared to $9 \%$ of non-leaders $(\mathrm{p}<0.01)$. Among men leaders, this percentage increases to $22 \%$ but only applies to $8 \%$ of women leaders.

Finally, leaders are also much more likely to be fairly or totally opposed to company board legislation $(33 \%)$ compared to $18 \%$ of non-leaders $(\mathrm{p}<0.01)$, but with a difference only among men and not women. These results signal an important disconnect between the assumption that men leaders are willing to act as agents of change and the fact that they are the group most opposed to such a change. Beliefs do not automatically translate into actions. However, if men at the top of the organisation are less likely to feel that women should be equally represented as leaders - even though they have the most power to change this - it ultimately means that they have the potential to exercise greater resistance, including through legislation or any other measure that is effective at tackling gender inequalities in leadership. 
The results of the SEM models (standardised coefficients) are presented in Table 3. Model 1 shows that essentialist gender beliefs are negatively related to support for legislated measures such as quotas or targets $(\beta=-0.210, \mathrm{p}<0.01)$, which supports Hypothesis 1 . Model 2 supports that higher levels of essentialist gender beliefs are associated with higher discriminatory gender beliefs $(\beta=0.375, \mathrm{p}<0.01)$. Model 3 suggests that both essentialist gender beliefs $(\beta=-0.103, \mathrm{p}<0.01)$ and discriminatory gender beliefs $(\beta=-0.293, \mathrm{p}<0.01)$ have a negative effect on support for legislated measures. In the next step, the mediation is assessed through Model 4. The path between essentialist gender beliefs and support for legislated measures remains statistically significant but has reduced significantly (from $\beta=$ 0.210 to $\beta=-0.106$, both $\mathrm{p}<0.01$ ) suggesting partial mediation and not fully supporting Hypothesis 2 that the relationship would be fully mediated by discriminatory gender beliefs.

Table 3 about here

Controlling for sex and leadership status shows that men as well as leaders have higher levels of discriminatory gender beliefs and are less likely to support the implementation of quotas or other legislated measures such as or targets. The moderating effect of men leaders on discriminatory gender beliefs and on support for quotas or targets is assessed through Model 5. The results show that the relationship between (Hypothesis 3a) essentialist gender beliefs and discriminatory gender beliefs is not moderated by the interaction of being a man and a leader. However, the relationship between essentialist gender beliefs and support for quotas or targets (Hypothesis $3 \mathrm{~b}$ ) is moderated by being a man and a leader $(\beta=-0.028, \mathrm{p}<0.01)$. 
The analysis supports the hypothesis that essentialist gender beliefs are negatively related to support for quotas or targets (Hypothesis 1), a relationship that is only partially mediated by discriminatory gender beliefs (Hypothesis 2). The results support the fact that among men leaders, the relationship between essentialist gender beliefs and not supporting quotas or targets is even more pronounced (Hypothesis 3b). In contrast, discriminatory beliefs are more prevalent among both men and among leaders separately, but the results do not provide evidence that the relationship is more pronounced among men leaders (Hypothesis 3a).

\section{Discussion}

In a context where the imposition of legislated quotas has proved highly divisive in the EU, this article has sought to examine how supporting them relates to gender beliefs specifically among men leaders. The article responded to calls to better understand women's underrepresentation as leaders by showing that discriminatory gender beliefs weaken support for targets or quotas particularly among men leaders.

We contribute to the literature on gender and management in two ways. First, the article showed that essentialist gender beliefs are associated with lower support for legislated measures such as quotas or targets. This is in line with the propositions of social justice theory, where all individuals regardless of whether they belong to an advantaged or disadvantaged group, legitimise an unequal social system through stereotypes and essential differences (Jost and Banaji, 1994; Jost et al., 2004). The relationship between essentialist gender beliefs and support for legislated measures such as quotas or targets was partially mediated by discriminatory gender beliefs, demonstrating that lack of support for legislated measures can be linked to structural discrimination and to more deliberate forms of exclusion 
for women. It is not that essentialist gender beliefs lower support for gender equality measures such as quotas or targets that is in itself problematic, but rather that it actually leads to discriminatory gender beliefs as to women's positions as leaders. It is important to make gender beliefs apparent, as they otherwise infuse gender relations in a manner that is pervasive and taken for granted when they are brought into social relations and practices (Martin, 2001).

Our second contribution builds on the relationship between gender beliefs and quotas as effective gender equality measures, through the examination of the extent to which these dynamics applied among men leaders. We examined this through the lens of social identity theory which focuses on the mechanisms that members of the advantaged group will use to reproduce an unequal system (Tajfel, 1981; Tajfel and Turner, 2004). Social identity theory can be understood in relation to social justification theory: rather than focus on all groups, it is concerned with the most advantaged group, and in doing so explains why the mechanism of justification is stronger among that group. The role of men as leaders is of relevance because they have the potential to enact change in organisational cultures and increase gender equality, or instead to continue to block progress and opt to reproduce existing inequalities. The results show that leaders' beliefs are more prejudiced: only $9 \%$ of the population believes that women should not be equally represented as leaders given equal competence, with this figure increasing to $17 \%$ among leaders. Post-hoc analyses that control for age show that this difference is not the result of a generational effect. Furthermore, the results of our analysis also show that the relationship with support for legislated measures is more negative for men leaders. Men leaders are also more prone to use gender beliefs as a justification to maintain an unequal system, presumably because some fear they might lose the ability to control who gets access to leadership positions and the reduction of their own possibilities to access such 
positions (Benschop and van den Brink, 2014). Since men leaders are more likely to be opposed to women's board representation than any other category, concerns that (some) men are hindering women at work are warranted (Cockburn 1991). Enacting change in organisations is thus not solely about getting more men involved but it is also about the need for men to change their mindset (Kelan, 2015). Men need to be involved, both from a point of principle but also because they are more likely to be in powerful positions. While it is has been questioned if men can indeed dismantle their own positions of power and privilege (de Vries 2015), this article has indicated that the mindsets of men in leadership positions are a good starting point for gender equality efforts. This has wider implications, as homophilic mechanisms also serve to exclude both women and men that are not part of the same social elite (Brown, 2016). Women and men representing diversity but not having the same habitus as power elites have even fewer chances of reaching board level.

The current mindset amidst both women and men continues to adhere to the idea that women are 'essentially' different from men, and to use this difference to justify their lack of representation in leadership. The empirical results show that this is stronger among men leaders. A key implication of this paper for policy and practice is therefore that the mindsets of men in leadership positions need to be changed because they have the power to enact change (de Vries, 2015; Kelan and Wratil, 2018). Ensuring that top men leaders endorse and support gender equality is crucial, not least because of the effort required, in intensity and how sustained it is over time (Lyness, 2002). For this to happen, (men) leaders need to realise that merit is not a gender-neutral concept. The findings of this research show unequivocally that gender beliefs are at odds with the assumption that organisations are gender neutral and meritocratic in nature. The current approach is to design gender equality measures, but these often fail because they leave the mindset of change agents intact. Challenging this mindset 
implies tackling the myth that organisations are meritocratic and expose the fact that the gendered nature of organisations by its very design supports men throughout their career (Bagilhole and Goode, 2001). Resistance to programmes aimed at tackling structural inequalities continues to be strong, on the basis that they are seen as helping women, but obscuring the taken for granted fact that men have always been the recipient of implicit support in organisations (van den Brink and Stobbe, 2009). Leaders, most of whom continue to be men, can play an important role in ensuring that the gender gap does not continuously progress all the way to the top (Fitzsimmons and Callan, 2016a). While organisational actors can play a key role, there needs to be a recognition that their role is limited insofar as they operate amidst larger societal forces shaping gender roles and expectations since childhood (Fitzsimmons and Callan, 2016b) which the gender beliefs examined in this paper reflect. Getting men to meaningfully engage as agents of change includes that men become aware of their own biases and the privilege that they enjoy (de Vries 2015). This is particularly relevant for top leaders but also of relevance for everyone with line managerial responsibility in an organisation.

Further research could explore those avenues for changing the mindset of men as leaders. It could explore what role executive education can play to ensure that men leaders are able to lead inclusively and how effective unconscious bias awareness trainings are. It should explore how men are not only excluding but also including others (Kelan, 2018). In order for gender equality in organisations to progress, understanding and supporting men to lead inclusively is central and this should not only focus on men in leadership positions but also on men in junior and middle management positions. Additionally, further research should explore how the mindset of men influences how gender relations in the private sphere unfold. It is also important to research how essentialist views that women hold influence 
gender relations. Further research should continue to examine the relationship between gender beliefs and actions. This could help understand better processes of resistance to change interventions in organisations and their limited success in challenging gender inequalities. Further research could also aim at creating measures for gender beliefs that allow for an examination that differentiates between implicit and explicit attitudes. Implicit gender biases might differ significantly from conscious responses that are malleable as they are subject to factors such as social desirability or impression management. Finally, this research could not disaggregate at the national level due to the low proportion of leaders within each country. The national landscape of public policies to support women's representation on board is highly dynamic and fast changing. Since evidence suggests that the national institutional system (Terjesen and Singh, 2008; Grosvold and Brammer, 2011; Terjesen et al., 2015) and actors and processes (Seierstad et al., 2017) differ greatly, further research should examine how the relationships tested in this article vary at the national level according to different systems and cultures with larger samples of leaders.

\section{Conclusion}

This article has pointed to the potentially damaging role that gender beliefs can play in promoting women's equal representation in leadership positions. It has examined the role of both essentialist and discriminatory gender beliefs in relation to support for legislated measures, particularly among men as leaders. Based on the empirical findings, we argue that the taken-for-granted assumption that men leaders act as agents of change ignores the extent to which gender beliefs hinder meaningful gender equality measures in organisations. We argue that this is not only because essentialist gender beliefs are seen as justification for preventing such measures but also because essentialist beliefs feed into discriminatory attitudes that in turn hinder support for effective measures. 
This represents a theoretical contribution to the literature on the role of men leaders as agents of change and their propensity for resistance (Kramer, Konrad, Erkut and Hooper, 2006). It also makes a methodological contribution as it incorporates attitudinal data instead of relying on demographic proxies (Carpenter et al., 2004). This article is timely in that it contributes to the very divisive debates taking place in the context of EU policy on the possible introduction of quotas to remedy women's chronic and serious underrepresentation.

\section{References}

Acker, J., 1990, "Hierarchies, jobs, bodies: A theory of gendered organizations". Gender \& Society, 4: 139-158.

Acker, J., 2000, "Revisiting class: Thinking from gender, race, and organizations". Social Politics: International Studies in Gender, State \& Society, 7: 192-214.

Acker, J., 2006, "Inequality regimes gender, class, and race in organizations". Gender \& Society, 20: 441-464.

Ashcraft, K.L., 2005, "Resistance through consent? Occupational identity, organizational form, and the maintenance of masculinity among commercial airline pilots". Management Communication Quarterly, 19: 67-90.

Bagilhole, B. and J. Goode, 2001, "The contradiction of the myth of individual merit, and the reality of a patriarchal support system in academic careers: A feminist investigation". European Journal of Women's Studies, 8: 161-180.

Baron, R.M. and D.A. Kenny, 1986, "The moderator-mediator variable distinction in social psychological research: Conceptual, strategic, and statistical considerations". Journal of Personality and Social Psychology, 51: 1173-1182.

Bem, S.L., 1993, The lenses of gender: Transforming the debate on sexual inequality. Yale University Press. 
Benschop, Y. and H. Doorewaard, 1998, "Covered by equality: The gender subtext of organizations". Organization Studies, 19: 787-805.

Benschop, Y. and M. van den Brink, 2014, "Power and resistance in gender equality strategies: Comparing quotas and small wins". In Kumra, S., R. Simpson and R.J. Burke (eds.), The Oxford handbook of gender in organizations. Oxford: Oxford University Press, pp. 332-352.

Benschop, Y. and M. Verloo, 2006, “Sisyphus' sisters: can gender mainstreaming escape the genderedness of organizations?". Journal of Gender Studies, 15: 19-33.

Bentler, P.M., 1990, "Comparative fit indexes in structural models". Psychological Bulletin, 107: $238-246$.

Bertrand, M., S.E. Black, S. Jensen and A. Lleras-Muney, 2014, "Breaking the glass ceiling? The effect of board quotas on female labor market outcomes in Norway". National Bureau of Economic Research. Discussion paper, Norwegian School of Economics, pp. 1-54.

Bilimoria, D., 2000, "Building the business case for women corporate directors". In Burke, R.J. and M.C. Mattis (eds.), Women on corporate boards of directors, Springer Netherlands, pp. $25-40$.

Billing, Y.D., 2011, “Are women in management victims of the phantom of the male norm?”. Gender, Work \& Organization, 18: 298-317.

Billing, Y.D. and M. Alvesson, 2000, "Questioning the notion of feminine leadership: A critical perspective on the gender labelling of leadership". Gender, Work \& Organization, 7: $144-157$.

Boone H.N. and D.A. Boone, 2012, “Analyzing Likert data”. Journal of Extension, 50: 1-5.

Bozionelos, N., 2005, "When the inferior candidate is offered the job: The selection interview as a political and power game”. Human Relations, 58: 1605-1631.

Brescoll, V.L., E.L. Uhlmann and G.E. Newman, 2013, "The effects of system-justifying motives on endorsement of essentialist explanations for gender differences". Journal of Personality and Social Psychology, 105: 891-908. 
Britton, D.M. and L. Logan, 2008, "Gendered organizations: Progress and prospects". Sociology Compass, 2: 107-121.

Broadbridge, A. and J. Hearn, 2008, "Gender and management: new directions in research and continuing patterns in practice”. British Journal of Management, 19: S38-S49.

Broadbridge, A. and R. Simpson, 2011, "25 years on: Reflecting on the past and looking to the future in gender and management research". British Journal of Management, 22: 470483.

Brown, S.E., 2016, There's Never Been A Better Time To Be a Woman? Gendered Discourses on the Route to the Boardroom. King's College London.

Brown, S.E., E. Kelan and A.L. Humbert, 2015, Opening the Black Box of Board Appointments: Women's and Men's Routes to the Boardroom. Retrieved from http://www.openingtheblackbox.co.uk

Browne, J., 2014, "The critical mass marker approach: Female quotas and social justice", Political Studies, 62: 862-877.

Carpenter, M.A., M.A. Geletkanycz and W.G. Sanders, 2004, "Upper echelons research revisited: Antecedents, elements, and consequences of top management team composition". Journal of Management, 30: 749-778.

Carter, D.A., B.J. Simkins and W.G. Simpson, 2003, "Corporate governance, board diversity, and firm value”. Financial Review, 38: 33-53.

Castilla, E.J. and S. Benard, 2010, “The paradox of meritocracy in organizations". Administrative Science Quarterly, 55: 543-676.

Clason D.L. and T.J. Dormody, 1994, "Analyzing data measured by individual Likert-type items". Journal of Agricultural Education, 35: 31:35.

Cockburn, C., 1991, In the way of women: Men's resistance to sex equality in organizations. Cornell University Press.

Connell, R.W., 1998, "Masculinities and globalization". Men and Masculinities, 1: 3-23. 
Connell, R.W. and J.W. Messerschmidt, 2005, "Hegemonic masculinity: Rethinking the concept". Gender \& Society, 19: 829-859.

Croasmun J.T. and L. Ostrom, 2011, "Using Likert-type scales in the social sciences". Journal of Adult Education, 40: 19-22.

Desaint, N. and M. Varbanova, 2013, "The use and value of polling to determine public opinion on GMOs in Europe”, GM Crops \& Food, 4: 183-194.

de Vries, J.A., 2015, "Champions of gender equality: female and male executives as leaders of gender change". Equality, Diversity and Inclusion: An International Journal, 34: 21-36.

Dezsö, C.L. and D.G. Ross, 2012, "Does female representation in top management improve firm performance? A panel data investigation”. Strategic Management Journal, 33: 10721089.

Eagly, A.H. and L.L. Carli, 2007, "Women and the labyrinth of leadership". Harvard Business Review, 85: 63-71.

Eagly, A.H. and L.L. Carli, 2016, "Gender and leadership: Introduction to the special issue". Leadership Quarterly, 27: 349-353.

Eagly, A.H. and J.L. Chin, 2010, "Diversity and leadership in a changing world". American Psychologist, 65: 216-224.

Eagly, A.H. and S.J. Karau, 2002, "Role congruity theory of prejudice toward female leaders". Psychological Review, 109: 573-598.

Ely, R.J., H. Ibarra and D.M. Kolb, 2011, "Taking gender into account: Theory and design for women's leadership development programs". Academy of Management Learning \& Education, 10: 474-493.

Ely, R.J., and D.E. Meyerson, 2000. "Theories of Gender in Organizations: A New Approach to Organizational Analysis and Change". Research in Organizational Behavior, 22: $103-151$.

Eriksson $\square$ Zetterquist, U. and D. Renemark, 2016, "Can changes to gender equality be sustained?". Gender, Work \& Organization, 23: 363-378. 
European Commission and European Parliament, 2014, "Eurobarometer 76.1 (2011)". GESIS Data Archive, Cologne. ZA5565 Data file Version 4.0.0.

European Commission, 2015, "Database - Women and Men in Decision-making". http://ec.europa.eu/justice/gender-equality/gender-decision-making/database/index_en.htm.

Fausto-Sterling, A., 1985, Myth of Gender: Biological Theories about Women and Men. New York: Basic Books.

Fitzsimmons, T.W. and V.J. Callan, 2016a, "Applying a capital perspective to explain continued gender inequality in the C-suite". The Leadership Quarterly, 27: 353-370.

Fitzsimmons, T.W. and V.J. Callan, 2016b, "CEO selection: A capital perspective". The Leadership Quarterly, 27: 765-787.

Gill, R., E. K. Kelan and C. M. Scharff, 2017, "A postfeminist sensibility at work". Gender, Work \& Organization, 24: 226-244.

Grosvold J. and S. Brammer, 2011, "National institutional systems as antecedents of female board representation: An empirical study". Corporate Governance: An International Review, 19: 116-135.

Hakim, C., 2000, Work-lifestyle choices in the 21st century: Preference Theory. Oxford: Oxford University Press.

Hambrick, D.C., 2007, "Upper echelons theory: An update". Academy of Management Review, 32: 334-343.

Hambrick, D.C. and P.A. Mason, 1984, "Upper echelons: The organization as a reflection of its top managers". Academy of Management Review, 9: 193-206.

Haslam, N., L. Rothschild and D. Ernst, 2002, "Are essentialist beliefs associated with prejudice?”. British Journal of Social Psychology, 41: 87-100.

Haslam, N. and J. Whelan, 2008, "Human natures: Psychological essentialism in thinking about differences between people”. Social and Personality Psychology Compass, 2: 12971312. 
Hearn, J., 2004, "Gendering men and masculinities in research and scientific evaluations". In Brouns, M. and E. Addis (eds.), Gender and excellence in the making, DG Research European Commission, Brussels, pp. 57-67.

Hekman, D.R., S.K. Johnson, M.D. Foo and W. Yang, 2017, "Does diversity-valuing behavior result in diminished performance ratings for non-white and female leaders?". Academy of Management Journal, 60: 771-797.

Heilman, M.E., 2001, "Description and prescription: How gender stereotypes prevent women's ascent up the organizational ladder". Journal of Social Issues, 57: 657-674.

Heilman, M.E. and A.H. Eagly, 2008, "Gender stereotypes are alive, well, and busy producing workplace discrimination". Industrial and Organizational Psychology, 1: 393398.

Hopt, K.J. and P.C. Leyens, 2004, "Board Models in Europe - Recent Developments of Internal Corporate Governance Structures in Germany, the United Kingdom, France, and Italy”. European Company and Financial Law Review, 1: 135-168.

Hu, L. and P.M. Bentler, 1999, "Cutoff criteria for fit indexes in covariance structure analysis: Conventional criteria versus new alternatives". Structural Equation Modeling: a Multidisciplinary Journal, 6: 1-55.

Huse, M. and M. Brogi, 2013, "Introduction”. In Machold, S., M. Huse, K. Hansen and M. Brogi (eds.), Getting women on to corporate boards: A snowball starting in Norway, Edward Elgar Publishing, pp. 1-8.

Huse, M., S.T. Nielsen and I.M. Hagen, 2009, "Women and employee-elected board members, and their contributions to board control tasks". Journal of Business Ethics, 89: 581597.

Husu, L., 2004, "Gate-keeping, gender equality and scientific excellence”. In Brouns, M. and E. Addis (eds.), Gender and excellence in the making, DG Research - European Commission, Brussels, pp. 69-76.

Jost, J.T. and M.R. Banaji, 1994, "The role of stereotyping in system-justification and the production of false consciousness". British Journal of Social Psychology, 33: 1-27. 
Jost, J.T., M.R. Banaji and B.A. Nosek, 2004, “A decade of system justification theory: Accumulated evidence of conscious and unconscious bolstering of the status quo". Political Psychology, 25: 881-919.

Kelan, E.K., 2015, Linchpin - Men middle managers and gender inclusive leadership. Cranfield: Cranfield School of Management.

Kelan, E.K., 2018, "Men doing and undoing gender at work: A review and research agenda". International Journal of Management Reviews, 20: 544-558.

Kelan, E.K. and A.L. Humbert, 2016, "Editorial: Gender in management research". British Journal of Management, Virtual Issue: Gender in Management Research.

Kelan, E.K. and P. Wratil, 2018, "Post-heroic leadership, tempered radicalism and senior leaders as change agents for gender equality". European Management Review, 15: 5-18.

Keller, J., 2005, "In genes we trust: The biological component of psychological essentialism and its relationship to mechanisms of motivated social cognition". Journal of Personality and Social Psychology, 88: 686-702.

Konrad, A.M. and F. Linnehan, 1995, "Formalized HRM structures: coordinating equal employment opportunity or concealing organizational practices?" Academy of Management Journal, 38: 787-820.

Kramer, V.W., A.M. Konrad, S. Erkut and M.J. Hooper, 2006, "Critical mass on corporate boards: Why three or more women enhance governance". Wellesley Centers for Women Boston.

Krefting, L.A., 2003, "Intertwined discourses of merit and gender: Evidence from academic employment in the USA". Gender, Work \& Organization, 10: 260-278.

Lagaert, S. and H. Roose, 2018, "Gender and highbrow cultural participation in Europe: The effect of societal gender equality and development". International Journal of Comparative Sociology, 59: 44 - 68.

Leong, C.H. and C. Ward, 2006, "Cultural values and attitudes toward immigrants and multiculturalism: The case of the Eurobarometer survey on racism and xenophobia". International Journal of Intercultural Relations, 30: 799-810. 
Lewis, P. and R. Simpson, 2017, "Hakim Revisited: Preference, Choice and the Postfeminist Gender Regime”. Gender, Work \& Organization, 24: 115-133.

Liff, S., L. Worrall and C.L. Cooper, 1997, "Attitudes to women in management: an analysis of West Midlands businesses”. Personnel Review, 26: 152-173.

Likert, R. 1932, “A technique for the measurement of attitudes". Archives of Psychology, 22: 55.

Lyness, K.S., 2002, "Finding the key to the executive suite: Challenges for women and people of color". In R. Silzer (ed.), The 21st century executive: Innovative practices for building leadership at the top, San Francisco, CA: Jossey-Bass, pp. 229-273.

Machold, S., M. Huse, K. Hansen and M. Brogi, 2013, Getting women on to corporate boards: A snowball starting in Norway, Edward Elgar Publishing.

Mannix, E. and M.A. Neale, 2005, "What differences make a difference?". Psychological Science in the Public Interest, 6: 31-55.

Martin, P., 2001, "Mobilizing masculinities': Women's experiences of men at work". Organization, 8: 587-618.

Martin, P.Y. and D. Collinson, 2002, “'Over the pond and across the water': Developing the field of 'gendered organizations"”. Gender, Work \& Organization, 9: 244-265.

McKinsey, 2012, Women Matter 2012: Making the Breakthrough, http://www.mckinsey.com/client_service/organization/latest_thinking/women_matter.

McPherson, M., L. Smith-Lovin and J.M. Cook, 2001, "Birds of a feather: homophily in social networks". Annual Review of Sociology, 27: 415-444.

Mor Barak, M.E., 2016, Managing diversity: Toward a globally inclusive workplace. Thousand Oaks, CA: Sage.

Morton, T.A., T. Postmes, S.A. Haslam and M.J. Hornsey, 2009, "Theorizing gender in the face of social change: Is there anything essential about essentialism?" Journal of Personality and Social Psychology, 96: 653-664. 
Nielsen, S., 2009, "Why do top management teams look the way they do? A multilevel exploration of the antecedents of TMT heterogeneity". Strategic Organization, 7: 277-305.

Nielsen, S. and M. Huse, 2010, "Women directors' contribution to board decision $\square$ making and strategic involvement: The role of equality perception". European Management Review, 7: 16-29.

Noon, M., 2007, "The fatal flaws of diversity and the business case for ethnic minorities". Work, Employment \& Society, 21: 773-784.

Padavic, I. and B.F. Reskin, 2002, Women and men at work. Thousand Oaks, CA: Pine Forge Press.

Post, C. and K. Byron, 2015, "Women on boards and firm financial performance: A metaanalysis". Academy of Management Journal, 58: 1546-1571.

Prime, J. and C.A. Moss-Racusin, 2009, Engaging men in gender initiatives: what change agents need to know, http://www.catalyst.org/publication/323/engaging-men-in-genderinitiatives-what-change-agents-need-to-know.

Ridgeway, C.L., 2001, “Gender, status, and leadership”. Journal of Social Issues, 57: 637655.

Sandberg, S., 2013, Lean in: Women, work, and the will to lead. London: W H Allen.

Schein, E.H., 2010, Organizational culture and leadership. San Francisco CA: Jossey-Bass.

Schein, V.E., 1973, "The relationship between sex role stereotypes and requisite management characteristics”. Journal of Applied Psychology, 57: 95-100.

Scully, M. A., 1997, “Meritocracy”. In Werhane, P. H. and R. E. Freeman (eds.), Blackwell Encyclopedic Dictionary of Business Ethics, Oxford: Blackwell, pp. 413-414.

Seierstad, C., 2013, "Gender quotas on corporate boards in Norway, necessary but not ideal". In Machold, S., M. Huse, K. Hansen and M. Brogi (eds.), Getting women on to corporate boards: A snowball starting in Norway, Edward Elgar Publishing, pp. 138-146. 
Seierstad C., G. Warner-Søderholm, M. Torchia and M. Huse, 2017, "Increasing the number of women on boards: The role of actors and processes". Journal of Business Ethics, 141: $289-315$.

Stafsudd, A., 2006, "People are strange when you're a stranger: senior executives select similar successors". European Management Review, 3: 177-189.

Storvik, A. and M. Teigen, 2010, Woman on board: The Norwegian experience. FriedrichEbert-Stiftung, Internat. Policy Analysis.

Tajfel, H., 1981. Human groups and social categories: Studies in social psychology. CUP Archive.

Tajfel, H. and J.C. Turner, 2004, "The social identity theory of intergroup behavior". In J.T. Jost, J. Sidanius (eds.), Political psychology: Key readings, New York: Psychology Press, pp. 276-293.

Terjesen S. and V. Singh, 2008, "Female presence on corporate boards: A multi-country study of environmental context". Journal of Business Ethics, 83:55-63.

Terjesen, S., R. V. Aguilera and R. Lorenz, 2015, "Legislating a woman's seat on the board: Institutional factors driving gender quotas for boards of directors". Journal of Business Ethics, 128: 233-251.

Terjesen, S. and R. Sealy, 2016, "Board gender quotas: Exploring ethical tensions from a multi-theoretical perspective". Business Ethics Quarterly, 26: 23-65.

Tienari, J., C. Holgersson, S. Meriläinen and P. Höök, 2009, “Gender, management and market discourse: The case of gender quotas in the Swedish and Finnish media". Gender, Work \& Organization, 16: 501-521.

Tucker, L.R. and C. Lewis, 1973, “A reliability coefficient for maximum likelihood factor analysis". Psychometrika, 38: 1-10.

Turner, J.C., M.A. Hogg, P.J. Oakes, S.D. Reicher and M.S. Wetherell, 1987, Rediscovering the social group: A self-categorization theory. Oxford: Basil Blackwell. 
Uhlmann, E.L. and G.L. Cohen, 2005, "Constructed criteria: Redefining merit to justify discrimination". Psychological Science, 16: 474-480.

van den Brink, M. and Y. Benschop, 2014, "Gender in academic networking: The role of gatekeepers in professorial recruitment". Journal of Management Studies, 51: 460-492.

van den Brink, M. and Y. Benschop, 2018, "Gender Interventions in the Dutch Police Force: Resistance as a Tool for Change?". Journal of Change Management, early view.

van den Brink, M. and L. Stobbe, 2009, "Doing gender in academic education: The paradox of visibility". Gender, Work \& Organization, 16: 451-470.

Vinkenburg, C.J., 2017, "Engaging gatekeepers, optimizing decision making, and mitigating bias: design specifications for systemic diversity interventions". The Journal of Applied Behavioral Science, 53: 212-234. 